\title{
Evaluation of Waste Water Treatment Units Located at Different Parts of Nepal
}

\author{
Janardan Lamichhane, Bimal B. Upadhyaya, Nishant Chalise and Sudeep Makaju \\ Department of Biotechnology, Kathmandu University, Dhulikhel, Kavre \\ e-mail: ljanardan@ku.edu.np
}

\begin{abstract}
Sewage including liquids from household waste to industry and commerce effluent along with storm water runoff carries various contaminants including soil particles, heavy metals, organic compounds, animals waste, oils and grease which are required to be treated before they are discharged directly to the water into waterways. Various waste water treatment plants established in different part of Nepal include small to large scale treatment of waste discharge. The evaluation of all those plants by scientific mean was carried out for the recommend of standard of treatment plant suitable to the country. Among the plants under study, removal efficiency of TSS, TDS and TS was found highest in KU reed bed systems with 97.5, 74.3 and 95.6\% respectively. Similarly, removal efficiency of chemical compounds such as $\mathrm{NH}_{3}, \mathrm{~N}_{2}, \mathrm{NO}_{3}{ }^{2-}, \mathrm{Cl}^{-}, \mathrm{PO}_{3}{ }^{2-}$ and $\mathrm{COD}$ were found highest in $\mathrm{KU}$ and $\mathrm{DH}$ reed bed system ranging from 98 to $33.3 \%$ whereas BOD was found highest, 93.1 and 82.1\% in HIDWTP and BASP respectively. $\mathrm{pH}$ and conductivity measurement and comparison indicates the requirement of continuous use and maintenance of the plant. This could be one of the major ways to inform the government about the maintenance, sustainability and importance of ongoing operation of waste water treatment plants of Nepal in cost effective manner.
\end{abstract}

Key words: biochemical oxygen demand (BOD), chemical oxygen demand (COD), total suspended solids (TSS)

\section{Introduction}

Research into the cleansing ability of wetlands began from Germany in 1950s. Wetlands are often highly productive systems where numerous biological transformations driven by the natural energies of the sun, wind, soil, microorganism, plants and animals occur (Wetzel 1993, Kadle et al. 1996, Hammer 1997, Mitsch et al. 2000). Nutrients and suspended solids from polluted water can be removed using wetlands (Kathe Seidel 1976, Kickuth 1970). Bulrushes (Schoenoplectus lacustris) could remove large quantities of organic and inorganic substances from contaminated water (Kathe Seidel 1976). It was also demonstrated that bulrushes can also reduce the levels of bacteria in waste water by secreting natural antibiotic substances from their roots, and they can sequester heavy metals and eliminate hydrocarbons.
Macrophyte based waste water treatment systems have several potential advantages compared with conventional treatment systems (Brix et al 1989). The use of duckweed species has been advocated due to their rapid growth rates (Alaerts et al. 1996). Similarly, constructed wetlands are designed and constructed to employ wetland vegetation to assist in treating wastewater in a more controlled environment.

Constructed wetlands are eco-friendly alternative for secondary and tertiary municipal and industrial wastewater treatment. Hammer $(1992,1989)$ defines constructed wetlands as a designed, man made complex of saturated substrate, emergent and submerged vegetation, animal life and water that 
simulate wetlands for human uses and benefits. In free water surface treatment wetlands, water flows over a vegetated soils surface from an inlet point to an outlet point. In some cases, water is completely lost to evapotranspiration and seepage within the wetland (Kadlec \& Knight 1996). Majority of existing subsurface flow wetland systems treating municipal wastewaters are preceded by either facultative or aerated ponds. Such ponds are selected to improve the water quality of the pond effluent and can provide very effective removal of both BOD and TSS. There is no need to provide for high level of removal of these constituents in preliminary treatments (Reed et al. 1988). Managing wetland vegetation is crucial to the sustainability of an effective surface flow wastewater treatment wetland. Maintaining the optimal ration of open water to vegetation of the desired species composition is basic for sustaining water quality treatment function, habitat value and effective mosquito management (Joan et al. 2005).

Constructed wetlands for the treatment of wastewater were introduced in Nepal in 1997 from Dhulikhel hospital. Now there are 12 sub-surface flow constructed wetland system in operation for treatment of gray water, wastewater and fecal sludge at household to institutional scale. Few years back, the government decided to install constructed wetland systems at eight small cities for treatment of municipal wastewater under urban environmental program funded by Asian Development Bank.

In this part of the research we have included two small waste water treatment plants used by Kathmandu University and Dhulikhel Hospital which contain natural reed bed system for the treatment of waste water and two large scale treatment plants for the waste water treatment of urban wastes (one Bagmati Area Sewage Project, BASP controlled by Kathmandu Metropolitan and other Hetauda Industrial District Waste water Treatment Plant, HIDWTP under the control of Hetauda Municipality, Makawanpur District, Nepal). Our work explains the state of these wastewater treatment systems at present and recommends for the proper maintenance. Based on the capacity of removal of contaminated materials in waster water on these various treatment units, this work also suggests the type of treatment units suitable for the effective treatment of waster water in Nepal.

\section{Methodology Water sample collection}

Water samples were collected in sterilized plastic bottles from the inlets and outlets from three different wastewater treatment plants (Kathmandu University and Dhulikhel Hospital- Dhulikhel, Bagmati Area Sewage Project- Kathmandu and Hetauda Industrial District Wastewater Treatment Plant - Hetauda). The inlet samples were collected at an interval of $10 \mathrm{~min}$ in a cleaned sample bottles at 7-9 am thinking the time as peak period of domestic use of water. Similar collection was done from the outlets of each site after two hours of collection from inlet sites. All the samples were properly sealed and transferred to the lab for their chemical tests.

\section{pH and conductivity}

$\mathrm{pH}$ and conductivity measurement of the samples were carried out by standard protocol (Gupta 2002). pH of each sample was measured using $\mathrm{pH}$ meter (pH211 microprocessor $\mathrm{pH}$ meter, Hanna instruments, India). Before measuring $\mathrm{pH}$ of each sample, the electrode was washed 3-4 times with distilled water and was calibrated. Conductivity measurement was carried out using conductivity meter (DDS-11AW microprocessor conductivity meter, Shanghai Ronbio Scientific Co. Ltd, China).

\section{Total suspended solids (TSS)}

TSS was measured by gravimetric method (Gupta 2002). A measured volume of sample was filtered through a known weight of filter paper (Whatman No.41). The residue left on the filter paper was dried at temperature of $80 \mathrm{C}$ for $24 \mathrm{~h}$ and the final weight of the filter paper was taken. The TSS value was measured using the formula,

TSS $=($ Final weight - Initial weight $) /$ volume of sample in $\mathrm{ml}$

\section{Total dissolved solids (TDS)}

The filtrate obtained during TSS test was subjected to evaporate in hot air oven at $105^{\circ} \mathrm{C}$ for $24 \mathrm{~h}$. After the complete evaporation, the final weight of the crucible which was weighted previously was taken. The TDS value was measured using the formula,]

TDS $=($ Final weight - Initial weight $) /$ volume of sample in $\mathrm{ml}$ 
After calculating both dissolved and suspended solid particles in the sample, the total solid (TS) content was measured (Gupta 2002).

$\mathrm{TS}=\mathrm{TSS}+\mathrm{TDS}$

\section{Nitrogen}

Nitrogen content in various samples of the sites was tested in different ways. Ammonia nitrogen content was measured by using colorimetric method in UV spectrophotometer (Mendham et al. 2000). Ten mililitre of each sample was diluted 10 times using distilled water and treated with Nesslers reagent and Rochelle salt. The volume was maintained to $50 \mathrm{ml}$ and left for $15 \mathrm{~min}$. for color development. The samples were then tested by spectrophotometer at $420 \mathrm{~nm}$. The level of ammonia nitrogen was deduced from a standard calibration (using ammonia solution; ammonium chloride). The concentration of nitrogen in the sample was calculated comparing with the standard curves obtained at the concentrations ranging from 0.1 to 0.8 mg/l.

Nitrogen associated with ammonia was calculated using the same standard curves prepared for ammonia nitrogen test using the conversion fraction of 1.22 as the molecular weight of ammonia is 17 whereas of nitrogen is 14 .

Presence of nitrogen as nitrate ion was measured preparing potassium nitrate solution as reference solution and measuring the concentration at $304 \mathrm{~nm}$ in UV spectrophotometer. Variously concentrated solution $(0.01 \mathrm{M}-0.001 \mathrm{M})$ of potassium nitrate solution was prepared and standard curve was obtained. The samples obtained from different sites were then observed at same wavelength and concentration was determined using the standard curves of potassium nitrate solution.

\section{Phosphorous}

Phosphorous measurement was done by converting the phosphate form of the content into orthophosphate which can determined by colorimetric method (Mendham et al. 2000). The standard curve of phosphate was prepared and the absorbance of the sample was tested at $690 \mathrm{~nm}$ in UV spectrophotometer. The phosphate content was calculated from the calibration of the standard solution.

\section{Chlorides}

Titrimetric method was used to calculate the chloride content in the sample (Mendham J. et al, 2000). Silver nitrate $\left(\mathrm{AgNO}_{3}\right)$ solution $(0.02 \mathrm{M})$ and sodium chloride $(0.02 \mathrm{M})$ were prepared. $\mathrm{AgNO}_{3}$ solution was standardized against standard solution of $\mathrm{NaCl}$. The standard solution of $\mathrm{AgNO}_{3}$ was is then titrated with the samples obtained from various sources using potassium chromate as an indicator. The end point was obtained by titration and the chloride content was calculated using the following formula:

Chloride in mg/l $=\left(\right.$ Normality of $\mathrm{AgNO}_{3} \times$ Vol. of $\mathrm{AgNO}_{3} \mathrm{x}$ $35.5 \times 1000) / \mathrm{ml}$ of aliquot taken

\section{Chemical oxygen demand (COD)}

Measurement of COD in a given sample was tested by using standard protocol (Mendham et al. 2000). From each of the sample, $20 \mathrm{ml}$ solution was taken and $10 \mathrm{ml}$ potassium dichromate solution was added along with $30 \mathrm{ml}$ of $\mathrm{H}_{2} \mathrm{SO}_{4}$ and a pinch of $\mathrm{AgSO}_{4}$ and $\mathrm{MgSO}_{4}$. All the contents were put on a reflux system connected with condenser and the flask was heated in a water bath for $2 \mathrm{~h}$. Then the flask was cooled and diluted the solution to $150 \mathrm{ml}$ by adding distilled water. Two to three drops of ferroin indicator solution was added and the solution was titrated against ferrous ammonium sulphate. At the end point, blue green color of the content was found to change in reddish blue. A blank distilled water sample was also measured by same means. The COD was calculated based on the following formula.

$\mathrm{COD}(\mathrm{mg} / \mathrm{l})=\{(\mathrm{B}-\mathrm{S}) \times \mathrm{N} \times 1000 \times 8\} /$ vol. of sample (ml)

Where B is the volume of ferrous ammonium sulphate for blank titration, $\mathrm{S}$ is the volume of ferrous ammonium sulphate for sample and $\mathrm{N}$ is the normality of ferrous ammonium sulphate.

\section{Biochemical oxygen demand (BOD)}

One liter distilled was aerated for one day to attain dissolved oxygen saturation. The content was kept at $20^{\circ} \mathrm{C}$ for another one day. one mililitre of each of phosphate buffer, $\mathrm{MgSO}_{4}$ solution, $\mathrm{CaCl}_{2}$ solution and $\mathrm{FeCl}_{3}$ solution were added on it. twenty mililitre of collected sample of one site was added on it. $\mathrm{pH}$ of the sample was adjusted by adding $1 \mathrm{~N}_{2} \mathrm{SO}_{4}$. The solution was divided into 2 sets of BOD bottles of $250 \mathrm{ml}$. one mililitre of allylthiourea solution was added to each 
bottle and closed the mouth of BOD bottles immediately using glass stopper. The dissolved oxygen content (DO) of one set was determined in situ following the Winkler's method of oxygen estimation and considered as $\mathrm{BOD}_{1}$ phase. Other set of water sample was left to BOD incubator at $20^{\circ} \mathrm{C}$ for 5 days. After 5 days the samples were taken out from the incubator and similar DO calculation was carried out. The differences in dissolved gave the biochemical oxygen demand value. $\mathrm{BOD}=\left(\mathrm{DO}_{1}-\mathrm{DO}_{5}\right) \times$ Dilution factor

\section{Results and Discussion}

$\mathrm{pH}$ measurement was recorded concerning on two major points (first inlet and last outlet) of each treatment plant. In reed bed system of Dhulikhel Hospital (DH) and Kathmandu University (KU), the $\mathrm{pH}$ of main inlets was found ranging from 7.4 to 7.7 whereas the $\mathrm{pH}$ of the main outlet was observed 7.2 to 6.26 respectively. HIDWTP and BASP, the $\mathrm{pH}$ range for each inlet was found ranging from 9.4 to 9.35 whereas the outlets $\mathrm{pH}$ was 7.94 to 8.06 respectively (Table 1).

Table 1. Comparative $\mathrm{pH}$ analysis of different water treatment plants

\begin{tabular}{|c|c|c|c|c|c|}
\hline S.N. & $\begin{array}{l}\text { Wastewater treatment } \\
\text { plant }\end{array}$ & \multicolumn{2}{|c|}{ Main inlet } & \multicolumn{2}{|c|}{ Main outlet } \\
\hline 2 & DH & 7.4 & 508 & 6.35 & 340 \\
\hline 4 & BASP & 9.35 & 1129 & 8.06 & 967 \\
\hline
\end{tabular}

All the treatment plants showed a reduction in $\mathrm{pH}$. However, a significant reduction in $\mathrm{pH}$ was observed in HIDWTP (Fig. 1). It was observed that the reduction in $\mathrm{pH}$ at high rate was due to the incomplete removal of ammonia from waste water which is aerobically converted to hydroxonium ion by Nitrosomonas bacteria and enhanced the acidity of the water. If the population of nitrobacterium is significantly low, a very drastic decrease in pH is observed (Mitchell 1996). Another reason is due to the trapping of ions within the sand particles or the absorption by the roots of Phragmites that changes the flow rate of $\mathrm{H}^{+}$and $\mathrm{OH}^{-}$ ions and hence chances the $\mathrm{pH}$ value. In activated sludge and natural stabilization system, the population of microorganism acting far hydrolytically in nitrogen removal process is responsible for the $\mathrm{pH}$ modification besides physical and chemical process involved in the system. The basic $\mathrm{pH}$ observed in industrial effluents is due to the effect of soap and detergents which renders high amount of $\mathrm{OH}^{-}$ions in the system.

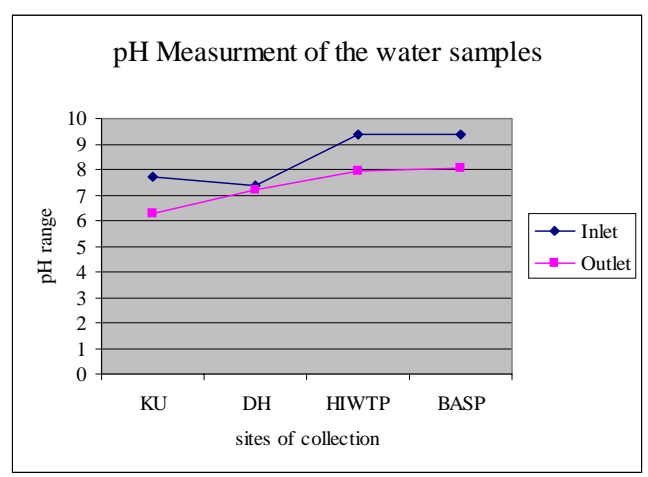

Fig 1. $\mathrm{pH}$ measurement of different water samples Conductivity of inlet samples from KU and DH were found as $559 \mu \mathrm{s} / \mathrm{cm}$ and $508 \mu \mathrm{s} / \mathrm{cm}$ and conductivity of the outlets of each system were found as $399 \mu \mathrm{s} / \mathrm{cm}$ and $340 \mu \mathrm{s} / \mathrm{cm}$ respectively. For HIDWTP and BASP the conductivity of the each sample of inlets and outlets for each site were found as $1262 \mu \mathrm{s} / \mathrm{cm}$ to 1129 $\mu \mathrm{s} / \mathrm{cm}$ and $1482 \mu \mathrm{s} / \mathrm{cm}$ to $967 \mu \mathrm{s} / \mathrm{cm}$ respectively (Table 2).

Table 2. Comparison of TSS, TDS and TS in different treatment plants

\begin{tabular}{c|c|c|c|c|c|c|c|c}
\hline \multirow{2}{*}{ Parameters } & \multicolumn{2}{|c|}{ KU } & \multicolumn{2}{c|}{ DH } & \multicolumn{2}{c}{ HIDWTP } & Out & In \\
\cline { 2 - 8 } & In & Out & In & Out & In & Out \\
\hline TSS (mg/l) & 3.092 & 0.076 & 5.028 & 0.536 & 2.220 & 0.240 & 3.42 & 0.644 \\
TDS (mg/l) & 0.280 & 0.072 & 0.100 & 0.040 & 0.456 & 0.230 & 0.67 \\
TS (mg/l) & 3.372 & 0.148 & 5.128 & 0.576 & 2.676 & 0.480 & 4.10 & 0.288 \\
\hline
\end{tabular}


Conductivity of wastewater is mainly due to the presence of free ions in it. Free ions as chemical pollutants are present in the inlet streams of most of the wastewater treatment units. The chemical processes carried on each treatment plant lead to decrement in conductivity as such. Except HIDWTP all the plants showed a significance decrease in conductivity value (Fig. 2). Free ions formed due to various processes like chemical reactions, adsorption of ions, nitrification enhances conductivity. Removal of nitrates, ammonium, heavy metals and other ions and associated chemicals decreases the free ion concentration. It was observed that ammonia concentration (result not shown) was found high in HIDWTP which might be the main reason of increase in conductivity compared to other treatment plants.

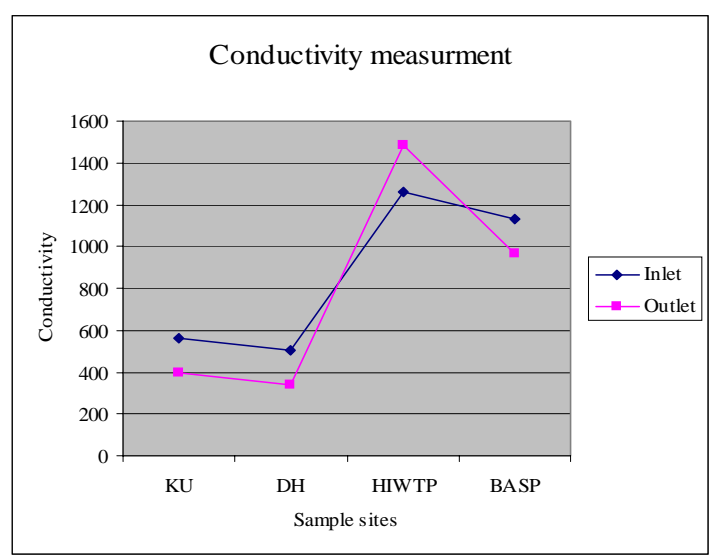

Fig 2. Conductivity measurement of water samples TSS measurements obtained from various systems showed that the TSS removal efficiency of reed bed system is better than treatment plant systems. In this study KU reed bed system showed highest efficiency compared to other reed bed system and treatment plants (Table 3). Similar result was obtained for TDS analysis. Efficiency of removal of the dissolved solids of KU was found in highest percentage compared to other three systems. Total solids (TS) calculated by summing the TSS and TDS in individual plants showed that inlet containing TS of DH, KU, HIDWTP and BASP were 5.128, 3.372, 2.676 and $4.1 \mathrm{mg} / \mathrm{ml}$ respectively whereas outlets were found to contain $0.576,0.148$, 0.48 and $0.932 \mathrm{mg} / \mathrm{ml}$ respectively (Table 3 ).

All treatment plants considered in this study are found to have higher efficiencies for the removal of TSS (Fig. 3). In all the wastewater treatment systems a settlement tank was found to be installed prior to proceeding into treatment system. Moreover, HIWTP was found to have natural stabilization system and a grid to remove floating particle while BASP was found to have grid to remove sand and similar particles brought due to the current of the water flow in the river. This might be the major caused to reduce suspended solids. In reed bed system sand and pebbles were found to be used which helps to trap the suspended solids. Stagnant water in aerated pools and oxidation ponds of activated sludge system and natural stabilization system respectively have performed as mimicry of settlement tanks as counter part of reed bed system. An Overwhelming removal efficiency (97\%) of KU reed bed compared to $\mathrm{DH}$ is due to the use of sand bed by KU with sand particles smaller than DH.

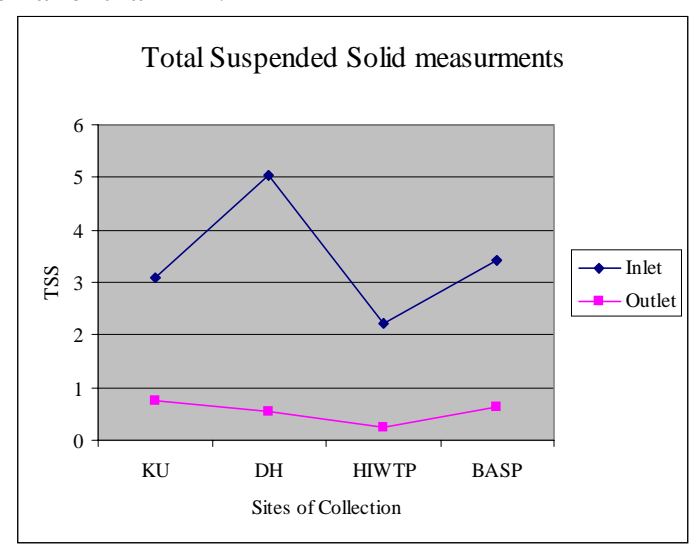

Fig.3. Total suspended solid measurement of samples

Removal of dissolved solids depends on biological degradation, microbial uptake, absorption, photolysis and abiotic degradation. Organic and inorganic carbon, dissolved nitrates and many other dissolved solids contribute to the total dissolved solids. Microbes present in the system uptake these solids as a source of their nutrients and also precursor of their metabolic pathways. Reed bed systems are found to have fully associated with all these removal mechanisms whereas some or few are found be associated with other treatment systems. Maximum retention time in stabilization ponds has led to enhanced photolytic activity to occur which is effective only for photosensitive compounds but not to all dissolved solids. By comparing the TSS, TDS and hence the TS value, KU has shown the highest removal efficiency which might be due to the balanced activities of all the necessary components to remove dissolved solids (Fig. 4). 
Table 3. Removal efficiency of solid particles

\begin{tabular}{c|l|l|l}
\hline \multirow{2}{*}{ Sample Sites } & \multicolumn{3}{|c}{ Removal efficiency \% } \\
\cline { 2 - 4 } & TSS (mg/l) & TDS (mg/l) & TS (mg/l) \\
\hline KU & 97.54 & 74.29 & 95.61 \\
DH & 89.34 & 60.00 & 88.77 \\
HIDWTP & 88.83 & 49.12 & 82.06 \\
BASP & 81.21 & 57.14 & 77.27 \\
\hline
\end{tabular}

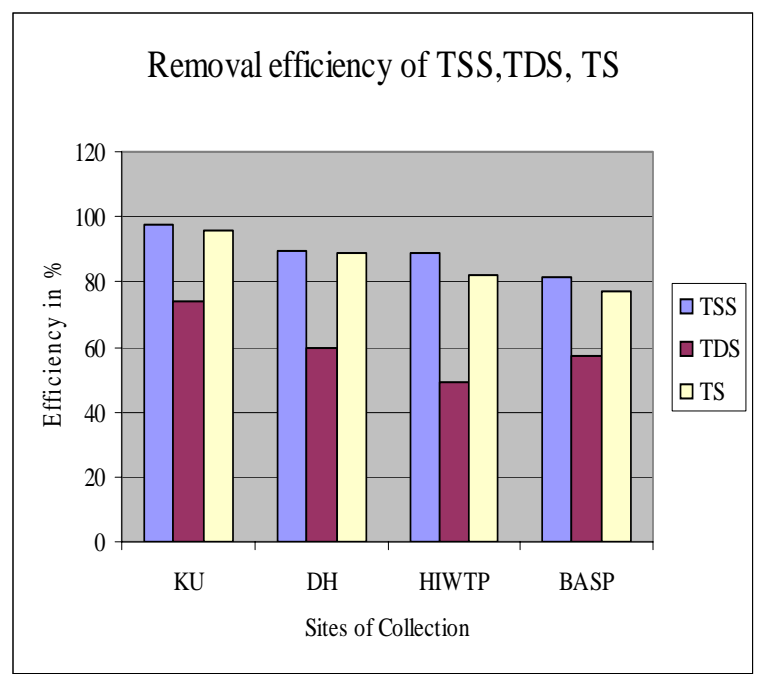

Concentrations of various chemical compounds measured by using different methods such as Nesselerization method for the analysis of ammonia and nitrogen associated with ammonia at $420 \mathrm{~nm}$ absorbance, ammonium molybdate method for the analysis of total phosphorous at $690 \mathrm{~nm}$ absorbance, nitrate at $304 \mathrm{~nm}$ absorbance, chloride concentration measurement by using silver nitrate titration method, open reflux method to calculate the chemical oxygen demand and Winkler's method used to calculate biochemical oxygen demand in the samples taken from KU, DH, HIDWTP and BASP showed the result (Table 4) that indicated the real efficiency of these wastewater treatment plants.

Fig. 4. Removal efficiency of TSS, TDS and TS

Table 4. Concentration of chemical compounds present in different water samples

\begin{tabular}{c|c|c|c|c|c|c|c|c}
\hline & \multicolumn{2}{|c|}{ KU } & \multicolumn{2}{c|}{ DH } & \multicolumn{2}{c|}{ HIDWTP } & \multicolumn{2}{c}{ BASP } \\
\hline Chemical & In & Out & In & Out & In & Out & In & Out \\
$\mathrm{NH}_{3}(\mathrm{mg} / \mathrm{l})$ & 11.712 & 6.799 & 15.14 & 0.302 & 22.74 & 125.24 & 54.68 & 48.32 \\
$\mathrm{~N}_{2}$ with NH & 9.6 & 5.573 & 12.41 & 0.247 & 18.64 & 102.66 & 44.82 & 39.6 \\
$\mathrm{PO}_{3}{ }^{2-}(\mathrm{ppm})$ & 1.923 & 0.978 & 1.416 & 0.795 & 1.15 & 0.704 & 0.714 & 0.341 \\
$\mathrm{NO}_{3}^{2-}(\mathrm{mg} / \mathrm{l})$ & 1831.88 & 2056.56 & 1818.76 & 1259.03 & 24409.76 & 19584.88 & 13359.44 & 8826.48 \\
$\mathrm{Cl}(\mathrm{mg} / \mathrm{l})$ & 40.47 & 26.98 & 40.47 & 26.98 & 69.58 & 59.64 & 79.52 & 69.58 \\
$\mathrm{COD}(\mathrm{mg} / \mathrm{l})$ & 654.36 & 24.6 & 521.52 & 88.56 & 1380 & 460 & 1288 & 552 \\
$\mathrm{BOD}(\mathrm{mg} / \mathrm{l})$ & 912.2 & 202.8 & 810.8 & 202.8 & 1450 & 100 & 140 & 25 \\
& & & & & & & & \\
\hline
\end{tabular}

The highest removal efficiency of nitrogen content in the form of ammonia was found in DH (Table 5) among KU, DH and BASP whereas the efficiency of HIDWTP could not be measured due to its high ammonia content in outlet than inlet. Ammonia in the form of nitrogen is continuously involved in transformation from inorganic to organic compounds and vice versa. During the process of transformation, plants and microbes uptake these compounds in the form of ammonium or nitrates. The growth status and phase of various microorganisms present in the treatment system is a major factor that determines the rate of removal of ammonium or nitrogen associated forms. The reed bed system, the growth of reed plants is also associated with nitrogen uptake. The highest ammonia removal efficiency of DH can be justified because of the reed plants in their growing phase and microbial action that played a significant role. KU is found to remove nitrogen related compounds relatively lower than $\mathrm{DH}$ which is because of almost matured reed plants. The uptake of ammonia as a source of nitrogen in this case is limited only for basic metabolisms rather than the 
growth of these plants. For KU reed bed system the effective removal of nitrogen related compounds can be done by recycling the plantation or at least cut off the branched of reed plants to assure growth. HIWTP was found to contain increased concentration of ammonium which signifies that BOD has been significantly reduced and there has been growth of algae in the outlet water. Algae show a mineralization process that converts organic nitrogen into inorganic forms, mainly ammonia nitrogen (IWA, 2000). Bacteria split off ammonia from amino acids in wastewater. Hydrolysis can take place where ammonia nitrogen is split off from urea and transforms into ammonia. This reaction depends on temperature, $\mathrm{pH}$ value, $\mathrm{C} / \mathrm{N}$ ratio, available nutrients and soil condition (IWA, 2000).

Table 5. Removal efficiency of different chemical compounds

\begin{tabular}{|c|c|c|c|c|c|c|c|}
\hline \multirow[t]{2}{*}{ Sample Sites } & \multicolumn{7}{|c|}{ Removal efficiency \% } \\
\hline & $\mathrm{NH}_{3}(\mathrm{mg} / \mathrm{l})$ & $\mathrm{N}_{2}(\mathrm{mg} / \mathrm{l})$ & $\mathrm{NO}_{3}{ }^{2-}(\mathrm{mg} / \mathrm{l})$ & $\mathrm{Cl}^{-}(\mathrm{mg} / \mathrm{l})$ & $\mathrm{PO}_{3}{ }^{2-}(\mathrm{mg} / \mathrm{l})$ & COD (mg/l) & BOD (mg/l) \\
\hline KU & 41.94 & 41.95 & & 33.33 & 49.14 & 96.24 & 77.77 \\
\hline $\mathrm{DH}$ & 98.01 & 98.01 & 30.78 & 33.33 & 43.94 & 83.02 & 74.99 \\
\hline HIDWTP & - & - & 19.77 & 14.29 & 38.78 & 66.67 & 93.10 \\
\hline BASP & 11.63 & 11.65 & 33.93 & 12.5 & 52.24 & 57.14 & 82.14 \\
\hline
\end{tabular}

Phosphorous can have secondary effects by triggering eutrophication within a wetland and leading to algal blooms and other water quality problems. Phosphorous may be present in the form of dissolved or particulate form while in outlet, its concentration mainly reduces due to leaching into the subsoil and by removal by plants and animal (Reddy et al, 1985, 1989). Phosphorous removal efficiency of BASP is highest followed by KU. Primary phosphorous removal mechanism includes adsorption, filtration and sedimentation. The lowest removal efficiency of phosphorous of HIDWTP can be explained by redox chemistry in which due to lack of proper facility for the aeration and low oxygen content in anaerobic and facultative lagoons, the phosphorous gets liberated into water from the sediments and soil back into water. The lagoons are deeper in anaerobic lagoon which blocks the sediments to receive appropriate amount of oxygen and retain phosphorous within them.

Nitrate that contributes for the total nitrogen content in wastewater is removed by denitrification process. Denitrification happens in wastewater treatment plant under anoxic or anaerobic conditions that converts nitrates into nitrogen and nitrous oxide by heterotrophic bacteria. These bacteria require $\mathrm{CO}_{2}$ as $\mathrm{C}$-donor for their growing process. In anaerobic condition nitrogen is used as an electron acceptor instead of oxygen. Besides, Pseudomonas species present in water can play role for the removal of nitrates. The population of these bacteria is found significantly high in anaerobic conditions. Whereas the concentration of nitrates is found to be high in aerobic condition due to the nitrification of ammonia.
KU reed bed systems showed increment in nitrate concentration in outlet which is due to the lack of sufficient population of the bacteria. The anaerobic lagoons (deeper ponds) where sediments rarely get oxygen have led the reduction in nitrate concentration in other treatment units which are deeper than KU reed bed system and have higher chances of being anaerobic.

Removal of chloride ions is associated with ion-ion interactions to stabilize chloride ions in the form of chloride salts and settle down along with suspended solids. Another mechanism is the involvement in adsorption and ion-exchange carried out by the plants and water content of the soil. KU and DH showed high chloride removal efficiency in compared to HIDWTP and BASP. The high content of chlorides in HIDWTP and BASP is due to the high concentration chloride in the water that the industries use for their various processing and also due to the less adsorption into suspended solids.

The value of COD depends on chemical contaminants in the water and amount of oxygen present in water. Chemical contaminants are higher in industrial effluents whereas the dissolved oxygen is very low. The high value of COD present in HIDWTP and BASP indicates the effect. The plants used in reed bed system have a characteristic to release oxygen during their physiological processes. Due to the reason such treatment systems help to reduce COD significantly. Low value of COD in DH and KU indicates the effect. BOD in these tests indicates the oxygen requirement in wastewater, effluents and polluted water. BOD 
measures the molecular oxygen utilized during a specified incubation period for the biochemical degradation of organic material and the oxygen used to oxidize inorganic materials such as sulfides and ferrous ions. It also measures the amount of oxygen used to oxidize reduced form of nitrogen such as ammonia and organic nitrogen. Oxidation of ammonia and organic nitrogen can be reduced by microorganism and exerts nitrogenous demand. Nitrogenous demand has been considered as interference in the determination of BOD. Natural stabilization system of HIDWTP showed highest BOD removal efficiency than mechanical activated sludge of BASP. Maximum algal growth observed in HIDWTP could be the reason of highest BOD removal. In wetland systems settled organic compounds are removed under quiescent condition by deposition and filtration. Organic compounds are degraded biologically (both aerobically and anaerobically) by heterotrophs and autotrophs depending on the oxygen concentration in the bed. In open and exposed system like HIDWTP and BASP dissolved oxygen content in water significantly rises compared to that in constructed wetlands. For this reason it is observed that the efficiencies of removal of BOD for HIDWTP and BASP were higher than the ones for KU and DH.

In conclusion, out of the three different treatment systems chosen in this study, each one showed their importance in removing unwanted materials in different ways. KU reed bed system showed high efficiency in removal of TSS (97.54\%), TDS (74.29\%), TS (95.61\%), Chlorides (33.33\%) and COD (96.24\%) whereas DH reed bed system showed its efficiency in removing ammonia nitrogen (98.01\%), Nitrogen (98.01\%) and Chlorides (33.33\%). Similarly, BASP showed its highest efficiency in removing total phosphorous (52.24\%) and nitrates (33.93\%) whereas HIDWTP showed its highest efficiency in BOD (93.10) removal. Thus, constructed wetlands such as KU reed bed showed its high efficiency in removal of various forms of waste water whereas mechanical and constructed activated sludge system also showed their importance in treating in large volume of municipal wastewater. Overall wastewater or sewage is a complex solution which may contaminate the human environment. Appropriate treatment and disposal of such contaminants is a prerequisite in order to avoid development of such conditions that may endanger the public health and welfare. The treatment technology should preferably be of lesser cost, easier to maintain and basically simple in construction and efficient functioning. An effective study of the most fruitful type of plants and their monitoring after establishment is essential.

\section{References}

Alaerts, G. J., M. Mahbubar Rahman and P. Kelderman. 1996. Performance analysis of a full-scale duckweed covered lagoon. Water Res. 30: 843-852.

Brix, H. and H. H. Schierup. 1989. The use of aquatic macrophytes in water pollution control. Ambio 18: 101-107.

Gupta, P.K. 2002. Methods in environmental analysis: water, soil and air. Agrobios Inc., India.

Hammer D.A. 1997. Creating freshwater wetlands, second ed. Lewis Publishers, Chelsea, MI, pp 831.

Hammer, D.A. and R.L. Knight.1992. Designing constructed wetlands for Nitrogen removal. In: Proceedings, third international conference wetland systems in water pollution control, University of New South Wales, Sydney, Australia. Pp. 3.1-3.37.

Hammer, D.A. 1989. Constructed wetlands for wastewater treatment: Municipal, industrial and agricultural. Lewis Publishers, Chelsea, MI. 831pp.

Joan, S.T., J.J. Sartoris and S.M. Nelson. 2005. Managing vegetation in surface-flow wastewater treatment wetlands for optimal treatment performance. Ecological engineering 25: 583-593.

Kadlec, R.H. and R.L. Knight. 1996. Treatment wetlands. CRC Press/ Lewis Publishers, Boca Raton, Florida.

Kickuth, R. 1970. Ecochemical capacities of higher plants. Naturwissenschaften 57(2): 55-61.

Mendham, J., R.C. Denney, J.D. Barnes and M. Thomas. 2000. Vogel's textbook of quantitative analysis Low price edition, Sixth edition, Pearson Education. London, UK.

Mitsch, W.J. and J.G. Gosselink. 2000. Wetlands, third edition. John Wiley and Sons Inc. New York, NY, pp 920.

Reddy, K.R. W.F.DeBusk. 1985. Nutrient removal potential of selected aquatic macrophytes. Jounal of Environmental Quality 14: 459-462.

Reddy, K.R., E.M. D’Angelo and T.A. DeBusk. 1989. Oxygen transport through aquatic macrophytes the role in wastewater treatment. Journal of Environmental Quality. 19: 261-267 
Reed, S.C., R.W. Crites and E.J. Middlebrooks. 1988. Natural systems for waste management and treatment. First edition. McGraw Hill book company, New York.

Seidel, K. 1976. Macrophytes and water purification. In: Biological control of water pollution. J (Tourbier and R.W. Pierson). Pennsylvania
University Press, Philadelphia, Pennsylvania. Pp. 109-122.

Wetzel, R.G. 1993. Constructed wetlands: scientific foundations are critical. In: Constructed wetland for water quality improvement. (Ed G.A. Moshiri ), Lewis Publishers, Boca Raton, FL. pp. 3-7 (chapter 1). 
Nepal Journal of Science and Technology 12 (2011) 201-110 